\title{
NON-SUICIDAL SELF-INJURY AMONG UNIVERSITY STUDENTS IN TURKEY: THE EFFECT OF GENDER AND CHILDHOOD ABUSE
}

\author{
Meltem Idig-Camuroglu ${ }^{1} \&$ Z. Belma Gölge ${ }^{2}$ \\ ${ }^{I}$ Bilted Psychotherapy Clinic, Ankara, Turkey \\ Istanbul University, Institute of Forensic Sciences, Cerrahpasa, Istanbul, Turkey
}

received: 6.7.2017;

revised: 15.5.2018;

accepted: 20.6 .2018

\begin{abstract}
SUMMARY
Background: The purpose of this study was to explore the effect of gender and childhood abuse on non-suicidal self-injurious (NSSI) behaviors among university students in Turkey.

Subjects and methods: In this study convenience sampling technique was used, the sample consisted of 1000 young adults who were from the eight universities in two big cities; Istanbul and Ankara. Besides with demographic questionnaire, Inventory of Statements about Self-Injury and Childhood Trauma Questionnaire were used.

Results: The prevalence of NSSI was $28.5 \%$ and the most prevalent three self-injurious behaviors were wound picking, banging/hitting and pinching self. There was not a gender difference in NSSI behavior frequency but in the type of behavior; males had significantly higher percentages of hitting and burning behavior. Examining the intrapsychic and interpersonal functions of NSSI, "affect regulation" and "toughness" functions were the most used ones among the participants. In terms of gender differences, "revenge" function was used by females more than males. Self-injurers had higher childhood abuse scores on sexual, physical, and emotional abuse and neglect subscales than non self-injurers, and males were significantly more abused than females.

Conclusions: Accepting childhood abuse as an important predictor of NSSI behavior, screening and assessment of abused children and adolescents can help to prevent the onset of the behavior.
\end{abstract}

Key words: non-suicidal self-injury - self-harm - childhood abuse - gender - university students

\section{INTRODUCTION}

Non-suicidal self-injury (NSSI), as a growing health concern around the world, has been increasingly common in individuals with no mental illness, especially among adolescents and university students (Hawton et al. 1997, White-Kress et al. 2004). A recent meta-analysis study with a systematic review showed that adolescents who have self-injurious thoughts and behaviors had a two-fold risk of dying by suicide (Castellvi et al. 2017).

Research on age of onset of NSSI behavior generally agreed on 12-14 years old (Deliberto \& Nock 2007, Glenn \& Klonsky 2010, 2011, Muehlenkamp \& Gutierrez 2004, Nock \& Prinstein 2004). However there is not enough research on duration and cessation of NSSI yet. The prevalence of NSSI differs according to the sample. Studies with adolescents and young adults have reported a wide range of rates for occasional NSSI; $4-17 \%$ (Baetens et al. 2011, Klonsky 2011, Klonsky et al. 2003, Morey et al. 2008, Nixon et al. 2008, Whitlock et al. 2006) and even $43.6 \%$ for repetitive NSSI (Hasking et al. 2008). In terms of gender, although many researchers (Hawton et al. 2002, Laye-Gindhu \& Schonert-Reichl 2005, Ross \& Heath 2002, Whitlock et al. 2006, Yates et al. 2008, Whitlock et al. 2011) showed that NSSI behavior is more common in females, some others (Andover et al. 2007, Gollust et al. 2008, Heat et al. 2008, Muehlenkamp \& Gutierrez 2004, van Camp et al. 2011) demonstrated no difference. On the other hand, in a few studies males reported higher rates of NSSI (Brunner et al. 2014, Toprak et al. 2011). In a recent meta-analysis, Bresin \& Schoenleber (2015) found that gender differences depended on the sample type; it was larger in clinical and younger samples than community and older samples. Women were also more likely to have a history of NSSI behavior than men.

In general, functions of NSSI are viewed as intrapersonal and interpersonal (Klonsky 2007a). The term intrapersonal refers to the functions aimed at changing an individual's internal state (emotions, thoughts and physical sensations), whereas the term interpersonal refers to functions that aim to alter the external setting, for example; withdrawal of demands or increased social support (Turner et al. 2012). In the vast majority of the research, participants reported intrapersonal functions, mainly, affect regulation (e.g. coping with negative emotions) and self-punishment (e.g. expression of anger at self) as the main functions (Gratz 2007, Klonsky 2007a, 2009, Klonsky \& Glenn 2009). Interpersonal or social functions were also reported however less frequently than intrapersonal ones. Among these, interpersonal influence (e.g. communicating internal distress to others) was the most often reported one (Klonsky 2007a, Nock \& Prinstein 2004), followed by revenge function, getting revenge against others (Klonsky 2007a). Nonetheless, it should be noted that one can utilize more than one function and functions can vary over time. 
Although the prevalence and forms are well studied, the possible pathways to NSSI behavior are still not understood clearly. Over the last two decades studies on childhood abuse frequently reported a relationship between abuse types and NSSI behavior (Croyle \& Waltz 2007, Gratz 2007, Whitlock et al. 2006, Yates 2004, Yates et al. 2008b).

It was stated by many researchers that the exposure to trauma in childhood has a prevailing effect in terms of biological, psychological, and social functioning (Briere \& Spinazzola 2005, Cicchetti \& Toth 2005, Suyemoto 1998, van der Kolk et al. 2005, van der Kolk et al. 1991, Walsh 2006, Walsh \& Rosen 1988, Yates 2004). Among the traumas, especially childhood abuse is reported as shaping the individual's sense of self in a self-destructive and re-traumatizing way (van der Kolk 1989). In other words, these individuals become attached to the experience of trauma and recreate that trauma by enacting violence against their own body through selfinjurious actions.

On the other hand, research on childhood abuse and NSSI behavior demonstrated inconsistent results; some declared that childhood physical abuse (Gratz \& Chapman 2007), emotional abuse and physical neglect (Goldstein et al. 2009), emotional abuse (Croyle \& Waltz 2007, Whitlock et al. 2006) and sexual abuse (Gratz 2007), sexual and physical abuse (Yates et al. 2008) and another study (Zoroğlu et al. 2003) reported all types of abuse were related to NSSI behavior. In a meta-analysis, Klonsky \& Moyer (2008) analyzed 43 studies and found that there was a relatively small relationship between childhood sexual abuse and self-injurious behavior. On the other hand, Fox et al. (2015) examined the risk factors for NSSI behavior in a meta-analysis and stated that childhood adversities are significantly related to NSSI. In a recent review, Smith et al. (2014) concluded that self-injury played a functional role in coping with trauma-related symptoms like negative emotions, unpleasant or intrusive thoughts or feelings. These contradictory data underlines the importance of further research to acquire more information; there is still little understanding about the relationship between childhood abuse and NSSI behavior and gender differences.

NSSI behavior is a new area of research in Turkey, for almost two decades only. Up until now, some studies searched the relationship between childhood traumas and NSSI behavior, however some of them were surveyed with only women (Akyüz et al. 2005), some had psychiatric patient samples (Evren \& Evren 2005, Baral et al. 1998) and some others (Zoroğlu et al. 2003, Evren et al. 2014, Oktan 2014, Somer et al. 2015) had high school student samples. There are only two studies with university populations; the first (Öksüz \& Malhan 2005) examined the health risk behaviors among university students. Toprak et al. (2011) studied the prevalence of self-harm and its relationship to suicidal ideation and suicide attempts. However none of these researchers used a valid and reliable tool for measuring NSSI behavior and its functions. Therefore, we can con- clude that the forms and functions of NSSI behavior and the effects of gender and child abuse on the behavior in a college population have not been studied systematically yet in our country, little is known especially about the functions of NSSI in non-clinical populations.

\section{Aims and Hypotheses of the Study}

Given the paucity of the research on the subject, our aim in this study was to analyze the prevalence, forms and functions of NSSI among university students in Turkey. We also aimed to document the effects of gender and child abuse on NSSI behavior. The hypotheses of the study are as follows:

H1. There is a gender difference in NSSI ratio and methods.

H2. Affect regulation is the most frequent intrapsychic function.

H3. Interpersonal influence is the most frequent interpersonal function.

H4. CTQ subscale points of non-suicidal self- injurers are higher than those who do not engage in NSSI.

\section{SUBJECTS AND METHODS}

\section{Subjects}

This research was conducted in the largest two cities of Turkey, Istanbul and Ankara, at state and private universities. In this study convenience sampling technique was used; participants were 1000 university students from four universities in each city. We aimed 1000 students and went on until we got a total of 1000 after we discarded 63 unusable and 58 uncompleted surveys. The students were from medicine, psychology, mathematics, sociology, IT, history, civil engineering and business administration majors during the 20122013 academic year. We contacted the university professors and explained the aim of the study and planned the data collection together. Only few $(2 \%)$ of the students refused to participate. Sixty-nine percent of the sample is female $(n=690)$ and $31 \%$ is male $(n=310)$. Of the sample, $46.1 \%$ is between $18-20$ years, $45.1 \%$ is 21 23 years old and $8.8 \%$ is 24 and older.

\section{Instruments}

The demographic questionnaire included age, gender, marital and socioeconomic status and parents' occupation. Two measures were used in this study; Inventory of Statements about Self-Injury and Childhood Trauma Questionnaire.

\section{Inventory of Statements about Self-Injury (ISAS)}

ISAS was developed by Klonsky and Glenn (2009) and contains two parts; in the first part, frequency of 12 self-harm behaviors which are performed deliberately and without suicidal intent are assessed. These beha- 
viors are; banging/ hitting self, biting, burning, carving, cutting, wound picking, needle-sticking, pinching, hair pulling, rubbing skin against rough surfaces, severe scratching, and swallowing chemicals. Participants are asked to estimate the number of times they have performed each behavior. Five additional questions assess descriptive and contextual factors, including age of onset, the experience of pain during self-harm, whether self-harm is performed alone or other people around, time between the urge to self-injure and the act, and whether the individual wants to stop self-injuring. The latter four have a multiple-choice format. In the second part 13 functions of the behaviors under two groups (intrapsychic and interpersonal) are assessed by 39 items. Five intrapsychic functions are emotion-regulation, anti-dissociation, anti-suicide, self-punishment, and marking distress. Eight interpersonal functions are; interpersonal boundaries, interpersonal influence, revenge, sensation seeking, peer-bonding, toughness, autonomy and self-care. Each function is assessed by three items, rated as "0-not relevant," "1-somewhat relevant," or "2-very relevant" to the individual's experience of self-harm. The reliability and validity study of ISAS is done by Klonsky and Glenn (2009) and internal consistency for intrapsychic and interpersonal functions are found .88 and .80 respectively. The reliability and validity study of the Turkish form was done by Bildik et al. (2013) and test-retest reliability was $r=0.66$. In the present study, internal consistency was 0.83 for intrapsychic and interpersonal functions part and 0.74 for behaviors part.

\section{Childhood Trauma Questionnaire (CTQ)}

The CTQ was developed by Bernstein and colleagues (1994) to assess abuse experienced before 18 years old. The test-retest reliability of the CTQ, over a two- to six-month period, has ranged from $\mathrm{r}=0.79$ to $\mathrm{r}=0.95$; and convergent and discriminant validity was determined to be adequate (Bernstein et al. 1994). Overall internal consistency of the entire measure was high $(\alpha=0.91$;
Scher et al. 2001). The Turkish form of CTQ is a 40item self-report measure on which respondents indicate, using a five-point Likert scale ranging from 1 (never true) to 5 (very often true), their childhood experiences as; (a) Emotional Abuse, (b) Physical Abuse, (c) Sexual Abuse, and (d) Emotional Neglect. The validity and reliability study of the Turkish form of CTQ was done by Aslan and Alparslan (1999). Each item starts with the stem "When I was a child". In the present study, internal consistency of the questionnaire was $\alpha=0.93$ and $\alpha=0.84, \alpha=0.72$, and $\alpha=0.92$ for Physical, Sexual, and Emotional Abuse and Neglect subscales respectively.

\section{Procedure}

First of all, this study was approved by the İstanbul University Ethics committee that human subjects will not be harmed. After the permission granted from the universities, a schedule was arranged by the researchers and the universities' professors. The researcher entered the classrooms and informed students about the aim of the study. Those who volunteered to participate signed an informed consent document. Afterwards they were given the demographic form and the instruments in an envelope and after completing, taken back as sealed thus, the anonymity was granted. The procedure took 15 minutes approximately.

\section{RESULTS}

\section{Prevalence and types of NSSI behavior}

Of the 1000 participants, 285 reported NSSI behavior at some point in their lifetime; $3.5 \%$ was occasional (only 1-2 times) and the rest $25 \%$ was repetitive selfharm. Overall, 186 (26.9\%) of 690 females, and 99 $(31.9 \%)$ of 310 males reported that they self-injured themselves at least once or more times. In terms of gender, there was not a significant difference $(\mathrm{x} 2: 1.68$, df: $1, \mathrm{p}>0.05)$. Of the self-injurers, $41.8 \%(\mathrm{n}=119)$ is $18-20,49.1 \%(n=140)$ is $21-23$ and $9.1 \%$ is 24 years old and older.

Table 1. Nonsuicidal self injury (NSSI) behaviors by gender

\begin{tabular}{lcccccc}
\hline & Female & $\mathrm{N}=186$ & \multicolumn{2}{c}{ Male } & $\mathrm{N}=99$ & \multicolumn{2}{c}{ Total } & $\mathrm{N}=285$ \\
& $\mathrm{~N}$ & $\%$ & $\mathrm{~N}$ & $\%$ & $\mathrm{~N}$ & $\%$ \\
\hline Wound-picking & 102 & 54.8 & 56 & 56.5 & 158 & 55.4 \\
Banging-Hitting Self* & 64 & 34.4 & 52 & 52.5 & 116 & 40.7 \\
Pinching & 59 & 31.7 & 29 & 29.2 & 88 & 30.8 \\
Biting & 57 & 30.6 & 26 & 26.2 & 83 & 29.1 \\
Hair pulling & 57 & 30.6 & 25 & 25.2 & 82 & 28.7 \\
Carving & 47 & 25.2 & 25 & 25.2 & 72 & 25.2 \\
Severe scratching & 54 & 29.0 & 17 & 17.1 & 71 & 24.9 \\
Cutting & 35 & 18.8 & 23 & 23.3 & 58 & 20.3 \\
Needle sticking & 25 & 13.4 & 18 & 18.1 & 43 & 15.0 \\
Rubbing skin & 24 & 12.9 & 10 & 10.1 & 34 & 11.9 \\
Swallowing chemicals & 21 & 11.2 & 10 & 10.1 & 31 & 10.8 \\
Burning** & 7 & 3.7 & 15 & 15.1 & 22 & 7.7 \\
\hline
\end{tabular}


Table 2. Mean and SD of NSSI behaviors

\begin{tabular}{|c|c|c|c|c|c|}
\hline & $\mathrm{N}$ & Min. & Max. & $\mu$ & SD \\
\hline Cutting & 58 & 1 & 100 & 9.53 & 0.89 \\
\hline Biting & 83 & 1 & 100 & 18.13 & 1.26 \\
\hline Burning & 22 & 1 & 20 & 5.59 & 0.46 \\
\hline Carving & 72 & 1 & 200 & 12.64 & 1.07 \\
\hline Pinching & 72 & 2 & 100 & 6.53 & 1.26 \\
\hline Hair pulling & 82 & 2 & 100 & 35.67 & 1.67 \\
\hline Severe scratching & 71 & 1 & 100 & 17.85 & 1.21 \\
\hline Banging/ Hitting Self & 116 & 1 & 100 & 18.83 & 1.39 \\
\hline Wound picking & 158 & 2 & 250 & 39.25 & 2.10 \\
\hline Rubbing skin & 34 & 1 & 100 & 17.00 & 0.83 \\
\hline Needle sticking & 43 & 1 & 100 & 12.23 & 0.86 \\
\hline Swallowing chemicals & 31 & 1 & 10 & 2.52 & 0.47 \\
\hline
\end{tabular}

Table 3. Descriptive features of NSSI behavior by gender

\begin{tabular}{|c|c|c|c|c|c|c|}
\hline & \multicolumn{2}{|c|}{ Female } & \multicolumn{2}{|c|}{ Male } & \multicolumn{2}{|c|}{ Total NSSI group } \\
\hline & $\mathrm{N}$ & $\%$ & $\mathrm{~N}$ & $\%$ & $\mathrm{~N}$ & $\%$ \\
\hline \multicolumn{7}{|c|}{ Experiencing pain during NSSI } \\
\hline Yes & 73 & 39.6 & 42 & 42.4 & 115 & 40.7 \\
\hline Sometimes & 77 & 42.0 & 41 & 41.5 & 118 & 41.6 \\
\hline No & 34 & 18.4 & 16 & 16.1 & 50 & 17.7 \\
\hline Total & 184 & 100.0 & 99 & 100.0 & 283 & 100.0 \\
\hline \multicolumn{7}{|c|}{ Being alone during NSSI } \\
\hline Yes & 83 & 44.6 & 51 & 51.6 & 134 & 47.0 \\
\hline Sometimes & 77 & 41.4 & 37 & 37.4 & 114 & 40.0 \\
\hline No & 26 & 14.0 & 11 & 11.0 & 37 & 13.0 \\
\hline Total & 186 & 100.0 & 99 & 100.0 & 285 & 100.0 \\
\hline \multicolumn{7}{|c|}{ Resisting to urge } \\
\hline$<1$ hour & 149 & 81.0 & 84 & 85.8 & 233 & 82.7 \\
\hline 1-3 hours & 22 & 12.0 & 8 & 8.1 & 30 & 10.6 \\
\hline 3-6 hours & 5 & 2.7 & 1 & 1.0 & 6 & 2.1 \\
\hline 6-12 hours & 3 & 1.6 & - & - & 3 & 1.1 \\
\hline$>1$ day & 5 & 2.7 & 5 & 5.1 & 10 & 3.5 \\
\hline Total & 184 & 100.0 & 98 & 100.0 & 282 & 100.0 \\
\hline \multicolumn{7}{|l|}{ Cessation need } \\
\hline Yes & 146 & 79.3 & 61 & 65.6 & 207 & 74.7 \\
\hline No & 38 & 20.7 & 32 & 34.4 & 70 & 25.3 \\
\hline Total & 184 & 100.0 & 93 & 100.0 & 277 & 100.0 \\
\hline
\end{tabular}

The most prevalent three NSSI behaviors were wound picking (55.4\%), banging/hitting self $(40.7 \%)$ and pinching $(30.8 \%)$. The least performed behavior was burning. The most common methods for genders were the same, however the least prevalent behaviors were different; it was burning for females $(3.7 \%)$ and swallowing chemicals for men $(10.1 \%)$. In terms of gender differences for methods, only burning $(\mathrm{X} 2=14.66$, $\mathrm{df}=2$, $\mathrm{p}<9.001)$ and hitting/banging $(\mathrm{X} 2=9.48, \mathrm{df}=4, \mathrm{p} \leq 0.05)$ behaviors were significantly different; males performed these methods more than females (Table 1). There was no significant difference in the other behaviors.

Means and SDs of NSSI behaviors were listed and wound picking ( $\mu=39.25 \pm 2.10)$, hair pulling ( $\mu=35.67 \pm$ 1.67), banging/ hitting self $(\mu=18.83 \pm 1.39)$ and biting $(\mu=18.13 \pm 1.26$ ) were the first four consecutively (Table 2).

Examining the number of methods used; it was found that almost half $(51.2 \%)$ of the self-injurers per- formed two behaviors $(25.6 \%$ one behavior and $26.6 \%$ two behaviors) and of the rest $16.8 \%(n=48)$ performed 3 behaviors, 15\% $(n=43) 4$ behaviors, 6\% $(n=17) 5$ behaviors and $11 \%(n=31) 6$ behaviors and more together. The onset of the behaviors was between 5 to 22 years old $(\mu=13.75, \mathrm{SD}=3.31)$. According to the results 14 years $(14 \%)$ and 15 years $(22.8 \%)$ of ages are the most common period for the onset. To determine the gender differences for the age of onset, independent samples t-test was conducted and a significant difference $(\mathrm{t}=1.93$, $\mathrm{df}=270, \mathrm{p}=0.05)$ was found between females $(\mu=14.03 \pm 3.41)$ and males $(\mu=13.22 \pm 3.10)$; males started earlier. Females reported the onset 5 to 22 , while males reported 5 to 20 years old of age.

The vast majority (87\%) of the group self-injured when they were alone, however, only $40.7 \%$ reported experience of pain during the act. Time elapsed between feeling the urge to injure oneself and acting was mostly 
$(82.7 \%)$ less than an hour. Most of the NSSI group $(74.7 \%)$ stated that they want to stop self-injurious behaviors and there was a significant difference in cessation need $(\mathrm{X} 2=6.12, \mathrm{df}=1, \mathrm{p}<0.01)$ between males $(\mathrm{n}=61)$ and females $(n=146)$. However there was no gender difference in terms of experiencing pain and being alone during NSSI act. Also no gender difference were found for time elapsed between urge and NSSI act (Table 3).

Nearly half $(51.9 \%)$ of the NSSI group had selfinjuring friends while, for the non-self-injuring group the ratio was one-third (34.6\%) only.

\section{Functions of NSSI}

Means and SDs of intrapsychic and interpersonal subscales of ISAS were calculated separately. For the intrapsychic functions, affect regulation was the most frequently $(\mu=2.40)$ used function by the self-injurers. Following were marking distress $(\mu=1.48)$ and selfpunishment ( $\mu=1.46$, Table 4$)$. There was no significant difference between genders in terms of intrapsychic functions. The most frequent interpersonal functions were toughness $(\mu=1.36)$, self-care $(\mu=1.19)$ and revenge $(\mu=1.12)$ in order (Table 5).

To determine the gender difference in interpersonal functions, independent samples $t$ tests were calculated. According to analyses, there was a significant difference $(\mathrm{t}=1.97 ; \mathrm{df}=279 ; \mathrm{p}<0.05)$ in the "revenge" func tion between genders; females had higher means (Table 5). For the other interpersonal functions, there was not a significant difference.

\section{NSSI and Childhood Abuse}

To examine the effects of NSSI behavior and gender, and the interaction of gender and NSSI behavior on sub-factors of CTQ, a 2 (gender: male, female) x 2 (NSSI; NSSI+, NSSI-) two- way ANOVA was conducted. Self-injurious behavior and gender were the independent variables and sub-factors of CTQ; physical abuse, sexual abuse, and emotional abuse and emotional neglect were the dependent variables. Table 6 shows the means and standard deviations for sub-factors of CTQ for NSSI+ (self-injurers) and NSSI- (non self-injurers) groups in the study divided by gender.

For emotional abuse and emotional neglect, there was not a significant gender $\mathrm{x}$ NSSI behavior interaction, $\mathrm{F}(1.999)=0.21, \mathrm{p}>0.05, \eta_{\text {partial }}{ }^{2}=0.00$. However, significant main effects were found for gender, $\mathrm{F}(1.1000)=47.36, \mathrm{p}<0.01$, and, self-injurious behavior, $\mathrm{F}(1.1000)=30.27, \mathrm{p}<0.01, \eta_{\text {partial }}{ }^{2}=0.29$.

For sexual abuse, there was a significant gender $\mathrm{x}$ NSSI behavior interaction $F(1.999)=7.19, p<0.01$, $\eta_{\text {partial }}{ }^{2}=0.02$, and significant main effects were found for gender, $F(1.999)=17.51, p<0.01, \eta_{\text {partial }}{ }^{2}=0.02$, and NSSI behavior, $\mathrm{F}(1.999)=42.80, \mathrm{p}<0.01, \eta_{\text {partial }}{ }^{2}=0.04$.

Table 4. Mean and SD of intrapsychic functions by gender

\begin{tabular}{lccccccccc}
\hline & \multicolumn{3}{c}{ Female } & \multicolumn{3}{c}{ Male } & \multicolumn{3}{c}{ Total } \\
Intrapsychic Functions & $\mathrm{N}$ & $\mu$ & $\mathrm{SD}$ & $\mathrm{N}$ & $\mu$ & $\mathrm{SD}$ & $\mathrm{N}$ & $\mu$ & $\mathrm{SD}$ \\
\hline Emotion Regulation & 182 & 2.43 & 2.01 & 97 & 2.42 & 1.83 & 280 & 2.40 & 1.86 \\
Anti-Suicide & 183 & 0.98 & 1.67 & 97 & 0.80 & 1.44 & 281 & 0.92 & 1.59 \\
Marking Distress & 183 & 1.60 & 1.86 & 97 & 1.26 & 1.61 & 281 & 1.48 & 1.78 \\
Self-Punishment & 182 & 1.52 & 1.77 & 98 & 1.38 & 1.67 & 281 & 1.46 & 1.73 \\
Anti-Dissociation & 183 & 1.18 & 1.64 & 97 & 1.21 & 1.49 & 281 & 1.18 & 1.59 \\
\hline
\end{tabular}

Table 5. Mean and SD of interpersonal functions by gender

\begin{tabular}{lccccccccc}
\hline & \multicolumn{3}{c}{ Female } & \multicolumn{3}{c}{ Male } & \multicolumn{3}{c}{ Total } \\
Intrapsychic Functions & $\mathrm{N}$ & $\mu$ & $\mathrm{SD}$ & $\mathrm{N}$ & $\mu$ & $\mathrm{SD}$ & $\mathrm{N}$ & $\mu$ & $\mathrm{SD}$ \\
\hline Interpersonal Boundaries & 183 & 0.80 & 1.32 & 98 & 0.81 & 1.27 & 282 & 0.80 & 1.30 \\
Interpersonal Influence & 183 & 0.83 & 1.23 & 98 & 0.67 & 1.28 & 282 & 0.77 & 1.25 \\
Revenge & 183 & 1.25 & 1.58 & 98 & 0.88 & 1.29 & 282 & 1.12 & 1.49 \\
Sensation Seeking & 183 & 0.63 & 1.19 & 98 & 0.90 & 1.43 & 282 & 0.72 & 1.28 \\
Peer Bonding & 183 & 0.28 & 0.83 & 98 & 0.32 & 0.99 & 282 & 0.29 & 0.89 \\
Toughness & 183 & 1.25 & 1.53 & 98 & 1.57 & 1.66 & 282 & 1.36 & 1.58 \\
Autonomy & 183 & 0.73 & 1.33 & 98 & 0.66 & 1.13 & 282 & 0.70 & 1.26 \\
Self- Care & 182 & 1.26 & 1.36 & 98 & 1.05 & 1.23 & 281 & 1.19 & 1.32 \\
\hline
\end{tabular}

Table 6. CTQ subscale mean and SD of NSSI+ and NSSI- groups

\begin{tabular}{|c|c|c|c|c|c|c|c|c|}
\hline \multirow{3}{*}{ CTQ } & \multicolumn{4}{|c|}{ NSSI+ group $(\mathrm{N}=285)$} & \multicolumn{4}{|c|}{ NSSI- group $\quad(\mathrm{N}=715)$} \\
\hline & \multicolumn{2}{|c|}{ Female $(\mathrm{N}=186)$} & \multicolumn{2}{|c|}{ Male $(\mathrm{N}=99)$} & \multicolumn{2}{|c|}{ Female $(\mathrm{N}=504)$} & \multicolumn{2}{|c|}{ Male $(\mathrm{N}=211)$} \\
\hline & $\mathrm{M}$ & $\mathrm{SD}$ & $\mathrm{M}$ & SD & $\mathrm{M}$ & $\mathrm{SD}$ & $\mathrm{M}$ & $\mathrm{SD}$ \\
\hline SA & 5.91 & 2.68 & 6.86 & 3.28 & 5.37 & 1.18 & 5.58 & 1.28 \\
\hline PA & 23.90 & 7.41 & 25.95 & 8.03 & 21.18 & 5.64 & 22.81 & 6.99 \\
\hline EA & 32.33 & 12.85 & 38.61 & 14.04 & 28.01 & 10.05 & 33.51 & 12.07 \\
\hline
\end{tabular}


For physical abuse; there was not a significant gender $\mathrm{x}$ self-injurious behavior interaction $\mathrm{F}(1.999)=0.19$, $\mathrm{p}>0.05, \eta_{\text {partial }}{ }^{2}=0.00$. However, significant main effects were found for gender, $F(1.999)=14.21, \quad p<0.01$, $\eta_{\text {partial }}{ }^{2}=0.02$, and self-injurious behavior, $\mathrm{F}(1.999)=36.02$, $\mathrm{p}<0.01, \eta_{\text {partial }}{ }^{2}=0.04$.

Analyses also showed that for all three types of trauma (physical abuse, sexual abuse, and emotional abuse/neglect), we found main effects of gender (more trauma reported by men) and main effects of NSSI (more trauma reported by the NSSI group). The interaction between gender and self-harm behavior was significant on the sexual abuse subscale of CTQ, but not on the physical abuse and emotional abuse and emotional neglect subscales of CTQ. Besides the difference between males and females and NSSI and non-NSSI group sexual abuse scores, the interaction between gender and NSSI behavior effects the sexual abuse scores significantly. There was a significant difference between the sexual abuse scores of NSSI females/ males and non NSSI females/males.

For a detailed perspective on the relationship between NSSI and CTQ subscales, further analyses were done. One sample Kolmogorov-Simirnov test was used to determine whether the variables were normally distributed. Later Spearman's rho analyses were used for the variables which were not normally distributed. To see the gender differences in relation between NSSI functions and CTQ, male and female groups were separately analyzed.

In intrapsychic functions, for females, a significant relationship was found only between anti-suicide $(\mathrm{r}=0.183, \mathrm{p}<0.05)$ and self-punishment $(\mathrm{r}=0.189, \mathrm{p}<0.01)$ functions and sexual abuse subscale. There was also a significant relationship between physical abuse subscale and emotion regulation $(\mathrm{r}=0.191, \mathrm{p}<0.01)$, anti-suicide $(\mathrm{r}=0.244, \mathrm{p}<0.001)$, marking distress $(\mathrm{r}=0.285, \mathrm{p}<0.001)$, self-punishment $(\mathrm{r}=0.297, \mathrm{p}<0.001)$ and anti-dissociation $(r=0.189, \mathrm{p}<0.01)$ functions. Finally, a significant relationship found between emotional abuse subscale and emotion regulation $(\mathrm{r}=0.174, \mathrm{p}<0.05)$, antisuicide $(\mathrm{r}=0.166, \mathrm{p}<0.05)$, marking distress $(\mathrm{r}=0.194$, $\mathrm{p}<0.01)$ and self-punishment $(\mathrm{r}=0.229, \mathrm{p}<0.01)$ functions. For males, there was only a significant relationship between physical abuse subscale and anti-suicide $(\mathrm{r}=0.364, \mathrm{p}<0.001)$, marking distress $(\mathrm{r}=0.282, \mathrm{p}<0.01)$, and self-punishment $(\mathrm{r}=0.215, \mathrm{p}<0.05)$ functions.

In interpersonal functions, for females, a significant relationship found only between interpersonal boundaries $(r=0.135, p<0.05)$ and revenge $(r=0.150, p<0.05)$ with sexual abuse subscale. There was also a significant relationship between physical abuse subscale and interpersonal boundaries $(\mathrm{r}=0.197, \mathrm{P}<0.01)$, interpersonal influence $(\mathrm{r}=0.204, \mathrm{p}<0.01)$ and revenge $(\mathrm{r}=0.186$, $\mathrm{p}<0.01)$ functions. A significant relationship found between interpersonal influence $(\mathrm{r}=0.179, \mathrm{p}<0.05)$, revenge $(\mathrm{r}=0.159, \mathrm{p}<0.05)$, peer bonding $(\mathrm{r}=0.164$, $\mathrm{p}<0.05$ ) functions with emotional abuse subscale. For males, there was only a significant relationship between physical abuse subscale and interpersonal boundaries $(\mathrm{r}=0.343, \mathrm{p}<0.001)$ function.

Furthermore, the correlations were calculated to determine if there was a relationship between CTQ subscales and other variables such as NSSI behavior frequency, age, duration of behavior, experiencing pain during the act and being alone or not. Analyses showed that for females, there was a significant relationship between behavior frequency and physical $(r=0.215$, $\mathrm{p}<0.001)$ and emotional abuse $(\mathrm{r}=0.174, \quad \mathrm{p}<0.001)$ subscale points. On the other hand, for males, a significant relationship found between behavior frequency and sexual $(\mathrm{r}=0.201, \mathrm{p}<0.001)$, physical $(\mathrm{r}=0.222, \mathrm{p}<0.001)$ and emotional abuse $(\mathrm{r}=0.185$, $\mathrm{p}<0.05)$ subscale points. As the CTQ subscale points increase, the frequency of NSSI behavior increase as well, both in males and female groups.

\section{DISCUSSION}

Our aim in this study was twofold; first to analyze the prevalence and functions of NSSI among university students in Turkey and second to investigate the effect of gender and childhood abuse on NSSI behavior. In this sample the prevalence of NSSI was $28.5 \%$; of this $25 \%$ was repetitive and only $3.5 \%$ was occasional. Thus, our finding is consistent with previous nonclinical sample studies (Baetens et al. 2011, Goldstein et al. 2009, Klonsky 2011, Klonsky et al. 2003, Morey et al. 2008, Nixon et al. 2008, Toprak et al. 2011, Evren et al. 2014, Whitlock et al. 2006). The most frequent NSSI behavior in our sample is wound-picking followed by hitting/banging self and pinching. In the similar studies, the most frequent behavior is mostly reported as cutting (Laukkanen et al. 2009, Heat et al. 2008, Goldstein et al. 2009, Hawton et al. 2007, Nixon et al. 2008). Studies done in Turkey also mostly reported cutting as the most frequent behavior (Akdemir et al. 2013, Özgan 2004, Uysal 2010). Oktan (2014), however, also used ISAS with an adolescent sample and reported wound-picking as the most common behavior.

Gender differences in NSSI behaviors has been a focus for many studies (Andover et al. 2010, Taylor 2003, van Camp et al. 2011, Whitlock et al. 2006, Whitlock et al. 2011). Accordingly, our findings partially supported the Hypothesis 1; there is not a gender difference in NSSI ratio however there is a gender difference in NSSI methods. As it was stated before, general opinion is that women self-injure more than men (Favazza \& Rosenthal 1993, Morey et al. 2008, Ross \& Heath 2002). In our sample, men had significantly higher percentages of some specific NSSI behaviors. In addition, the effect of gender was also apparent in age of onset and methods chosen; men started earlier to NSSI than women and chose more serious behaviors like burning and hitting. These results are also consistent with existing studies; the literature demonstrated that men preferred more serious behaviors than women (Andover et al. 2010, Dellinger-Ness \& 
Handler 2007, Taylor 2003). Nevertheless, the previous studies performed in Turkey demonstrated a different picture; while a study performed on Turkish high school students showed no gender difference in terms of NSSI (Zoroğlu et al. 2003), some studies even stated that NSSI was more common among male college students (Toprak et al. 2011, Oksuz \& Malhan 2005). Further, Robertson et al. (2013) demonstrated the importance of the number of the methods of NSSI used by an individual. In our sample most of the self-injurers used two methods together.

Although functions of NSSI is a growing body of knowledge, the number of the studies is still limited. Some researchers (e.g. Turner et al. 2012) asserted that self-injurers do engage this behavior for more than one function. Klonsky and Glenn (2009) classified the functions of NSSI as intrapsychic and interpersonal. Many researchers (Haas \& Popp 2006, Klonsky 2009, Nock 2009, Polk \& Liss 2007, Scoliers et al. 2009) demonstrated that the most frequently favored intrapsychic function of NSSI is affect regulation. This function refers to coping with negative thoughts and emotions; reducing or evading them. Our findings are consistent with literature; affect regulation was the most frequent intrapsychic function for this sample. Thus the second hypothesis is also justified.

Engagement in NSSI behavior is also mostly reported for "interpersonal influence" in terms of interpersonal functions (Klonsky 2007a, Nock \& Mendes 2008). However, hypothesis 3 is not supported; although we expected "interpersonal influence" be the most frequent interpersonal function, instead, it is "toughness". This function shows the endurance to pain, proving the strength and power of person to other people (Glenn \& Klonsky 2009). Previous research on the suggested functions of NSSI has shown that individual differences can statistically predict engagement in NSSI for intrapsychic vs. interpersonal functions. For example, high physiological arousal in response to stress (i.e., suicide attempts) are mainly related with the intrapsychic functions of NSSI, while the experience of social problems is predictive of the interpersonal functions (Nock \& Mendes 2008, Nock \& Prinstein 2004). Therefore we can interpret our finding as a result of social necessity of toughness function among Turkish young adults.

Nock et al. (2009) indicated that there was no gender differences in engagement in intrapsychic and interpersonal functions. Nevertheless, our study revealed a gender difference in interpersonal functions; there was significantly more engagement in "revenge" function by women. Revenge function involves retribution, trying to hurt someone close and expressing aggressive impulses by turning them into one's own body (Glenn \& Klonsky 2009). On the other hand, Oktan (2014), reported a gender difference in intrapersonal functions, female participants engaged more in "self-punishment" function. These contradictory findings definitely underline the necessity of more research on gender differences of functions of NSSI.
Child abuse literature has long revealed a positive relationship between maltreatment and NSSI behavior (D'onofrio 2007, Matsumoto et al. 2004, van der Kolk et al. 1991, Whitlock et al. 2006). Consistent with the previous studies, hypothesis 4 is also supported; it was determined that the NSSI behavior had a main effect on sexual, physical and emotional abuse. Sexual, physical and emotional abuse scores of non-suicidal self-injurers are higher than those who do not engage in NSSI behavior. This finding is consistent with Zoroğlu et al. (2003) study; they concluded that NSSI and higher trauma rates were correlated. In terms of gender, men reported more abuse on all subscales than women did in this sample. On the other hand, the literature shows contradictory results; while some researchers (e.g. Iffland et al. 2013) determined that women were more abused sexually, the others (e.g. Hovens, et al. 2010, Shi 2013) reported that women were exposed to abuse on all subtypes; sexual, physical, emotional and neglect.

At the beginning of this study, we had not planned to search the relationship between the childhood abuse and NSSI functions, therefore we did not include any hypothesis in this direction. Nevertheless, since our results supported the abuse trauma literature, we decided to discuss them as well, as it might start a new research interest. Our results pointed out a relationship between all types of abuse sub-scales and affect regulation, anti- dissociation, self-punishment, marking distress, revenge and anti-suicide functions for females. However, for males there was only a significant relationship between physical abuse sub-scale and antisuicide, marking distress, and self-punishment interpersonal boundaries functions. Therefore, based on this data, we can conclude that for females NSSI behavior is related to more trauma. Since there is not enough research on functions and gender yet, this study can start a new interest in the literature. Some research indicated that intrapersonal functions are related to traumatic stress (Klonsky \& Glenn 2009), emotional abuse (Rallis et al. 2012) and sexual abuse (Kaes et al. 2013).

In general, our results, particularly the relationship between affect regulation, anti- dissociation, selfpunishment and anti-suicide functions and CTQ supports the approaches explaining the relationship between NSSI and childhood abuse. According to Herman (1992) affect regulation function is interrupted in abused children due to the traumatic experience. When abuse gets chronic, child learns to stimulate her/his own body to end this dysfunction. The most dramatic type of stimulating oneself is NSSI behavior. Many abuse victims who engage in NSSI behavior describe a dissociative state and a need to prove that $\mathrm{s} /$ he is alive prior to the behavior. van der Kolk (1989) states that self-destructive acts are common among abused children. To balance the hyperarousal, as a result of being traumatized, and to stimulate endogenous opioid systems, abuse victims engage in NSSI behavior. Another interpretation comes from Finkelhor and Browne (1985), asserting that abuse victims view themselves as damaged and different than 
other people. That is why they are raged at their own bodies and try to punish and harm them by self-injuring.

One of the purposes of NSSI behavior is to differentiate the self from others which is performed by interpersonal boundaries function. According to boundaries model which is rooted in object relations theory, people who had parental empathy failure are unable to form stable object representations. As a consequence, boundaries become blurred and fear of merger occurs. Since the skin is the most basic boundary between self and other, NSSI behavior serves to draw a line while blood and scars are the marks of self-reality (Suyemoto 1998, Motz 2008).

Interpersonal influence function serves to impress and manipulate people around. It also help people to get attention and concern of others, escaping from negative environments, and works for help seeking behavior (Glenn \& Klonsky 2009).

Our study also showed evidence for the relationship between sexual abuse and interpersonal boundaries function besides with the relationship between emotional and physical abuse and interpersonal influence.

Instead of functions which refer to reasons like social learning/socializing (for example; peer-bonding, toughness or autonomy), identifying a relationship between CTQ and interpersonal functions, specifically; interpersonal influence, interpersonal boundaries and revenge functions which we can relate to emotional abuse and neglect, underlines the fact that further detailed research is needed.

\section{Limitations}

The data was gathered through retrospective selfreport, which has well-known limitations, like forgetting, recall bias and social desirability. As Hardt and Rutter (2004) pointed out the main concern in retrospective reports of adverse childhood experiences is that general tendency is not to report experiences of abuse. Therefore self-reports tend to lead to underestimation of abuse/neglect. It is also true for NSSI behavior, single methods can overlook cases, thus, for the NSSI behavior and childhood abuse, other sources of information, such as clinical interviews, could have strengthened results. Nevertheless due to large number of the participants we could not carry it out.

Furthermore, this study was planned to search the prevalence of NSSI and childhood abuse as one of the reasons of this behavior. The results of the study demonstrates the relationship between them however does not explain the causality. This could be stated as the limitation of our study. To determine the relationship between NSSI and childhood abuse, we can suggest broader quantitative research in which other variables are also included. That is how we can estimate if childhood abuse a strong predictor of NSSI behavior. Moreover, qualitative research can also help to understand the possible pathways to engagement in functions-both intra and interpersonal.

\section{CONCLUSIONS}

To conclude, we can state that NSSI is quite common among university populations, it might even be more frequent than it is reported. However we still do not have enough precise data to be able to have a broader perspective about the phenomenon.

In this study, we found that the vast majority $(74.7 \%)$ of self-injurers want to quit the behavior which can be interpreted finding as a need for help. With the help of research, preventions and interventions for NSSI and risk groups can be both identified and planned. Although NSSI is seen more frequently in psychiatric populations like depressive disorders, borderline personality disorder, eating disorders, etc., it is not eliminated easily by the treatment of comorbid disease. Direct interventions for NSSI behavior should be developed to decrease the harm (Aksoy \& Ogel 2003).

Furthermore, accepting childhood abuse as an important predictor of NSSI behavior, screening and assessment of abused children and adolescents can help to prevent the onset of the behavior. Basing prevention strategies in schools can be easier and more effective since children and adolescents spend a lot of time in there. Thus we can raise awareness in youth about NSSI and teach them how to seek professional help.

\section{Acknowledgements: None.}

\section{Conflict of interest: None to declare.}

\section{Contribution of individual authors:}

Meltem Idig-Camuroglu: Design of the study, data collection, writing manuscript;

Z. Belma Gölge: Approval of the last draft and statistical analyses.

\section{References}

1. Akdemir D, Zeki A, Ünal DY, Kara $M$ ve Çetin FÇ: Kendine zarar verme davranışı olan ergenlerde psikiyatrik belirtiler, kimlik karmaşası ve benlik saygisı. Anadolu Psikiyatri Dergisi 2013; 14:69-76

2. Aksoy $A$ \& Ögel $K$ : Kendine zarar verme davranışl. Anadolu Psikiyatri Dergisi 2003; 4:226-236

3. Akyüz G, Sar V, Kugu N \& Doğan O: Reported childhood trauma, attempted suicide and self-mutilative behavior among women in the general population. European Psychiatry 2005; 20:268-273

4. Andover MS, Pepper CM \& Gibb, BE: Self-mutilation and coping strategies in a college sample. Suicide \& Life Threatening Behavior 2007; 37:238-243

5. Andover MS, Primak JM, Gibb, BE \& Pepper C: An examination of non-suicidal self-injury in men: Do men differ from women in basic NSSI characteristics? Archives of Suicide Research 2010; 14:79-88

6. Aslan HS \& Alpaslan NZ: Çocukluk örselenme yaşantıları ölçeğinin bir üniversite öğrencisi örnekleminde geçerlik, 
güvenirlik ve faktör yapısı. Türk Psikiyatri Dergisi 1999; 10:275-285

7. Baetens I, Claes L, Muehlenkamp J, Grietens $H \&$ Onghena P: Non-suicidal and suicidal self-injurious behavior among Flemish adolescents: A web survey. Archives of Suicide Research 2011; 15:56-67

8. Bernstein DP, Fink L, Handelsman L, Foote J, Lovejoy M, Wenzel $K$ et al.: Initial reliability and validity of a new retrospective measure of child abuse and neglect. American Journal of Psychiatry 1994; 151:1132-1136

9. Baral I, Kora K, Yüksel Ş \& Sezgin U: Self-mutilative behavior of sexually abused female adults in Turkey. Journal of Interpersonal Violence 1998; 4:427-437

10. Bildik T, Somer O, Başay, B, Başay Ö \& Özbaran B: Kendine zarar verme davranışl değerlendirme envanterinin Türkçe formunun geçerlik ve güvenirlik çalışmast. Türk Psikiyatri Dergisi 2013; 24:49-57

11. Bresin K \& Schoenleber M: Gender differences in the prevalence of non-suicidal self-injury: A meta-analysis. Clinical Psychology Review 2015; 38: 55-64

12. Briere J, \& Spinazzola J: Phenomenology and psychological assessment of complex posttraumatic states. Journal of Traumatic Stress 2005; 18:401-412

13. Brunner R, Kaes M, Parzer P, Fischer G, Carli D et al.: Life-time prevalence and psychosocial correlates of adolescent direct self-injurious behavior: A comparative study of findings in 11 European countries. Journal of Child Psychology and Psychiatry 2014; 55:337-348

14. Castellvi P, Lucas-Romero E, Miranda-Mendizabal A, Pares-Badell O, Almenera J, et al.: Longitudinal association between self-injurious thoughts and behaviors and suicidal behavior in adolescents and young adults: A systematic review with meta-analysis. Journal of Affective Disorders 2017; 215:37-48

15. Cicchetti D \& Toth SL: Child maltreatment. Annual Review of Clinical Psychology 2005; 1:409-438

16. Croyle KL \& Waltz J: Subclinical self-harm: Range of behaviors, extent, and associated characteristics. American Journal of Orthopsychiatry 2007; 77:332-342

17. Deliberto TL \& Nock MK: An exploratory study of correlates, onset, and offset of non-suicidal self-injury Archives of Suicide Research 2007; 12:219-231

18. Dellinger-Ness LA \& Handler L: Self-Injury, gender and loneliness among college students. Journal of College Students 2007; V.10:142-152

19. D'onofrio AA: Adolescent Self-Injury, a Comprehensive Guide for Counselors and Health Care Professionals. 2007; New York: Springer

20. Evren C\& Evren B: Self-mutilation in substance-dependent patients and relationship with childhood abuse and neglect, alexithymia and temperament and character dimensions of personality. Drug and Alcohol Dependence 2005; 80:15-22

21. Evren C, Evren B, Bozkurt M \& Can Y: Non-suicidal selfharm behavior within the previous year among 10th-grade adolescents in Istanbul and related variables. Nordic Journal of Psychiatry 2014; 68:481-487

22. Favazza AR \& Rosenthal RJ: Diagnostic issues in selfmutilation. Hospital and Community Psychiatry 1993; 44:134-140

23. Finkelhor $D \&$ \& Browne A: The traumatic impact of child sexual abuse: A conceptualization. American Journal of Orthopsychiatry 1985; 55:530-541
24. Fox KR, Franklin JC, Riberio JD, Kleiman EM, Bentley $K H \&$ Nock MK: Meta-analyses of risk factors for nonsuicidal self-injury. Child Psychology 2015; 42:156-167

25. Glenn CR \& Klonsky ED: A Multi-method analysis of impulsivity in non-suicidal self-injury. Personality Disorders: Theory, Research, and Treatment 2010; 1:67-75

26. Goldstein AL, Flett GL \& Wekerle C: Personality, child maltreatment and substance use: Examining correlates of deliberate self-harm among university students. Canadian Journal of Behavioral Science 2009; 41:241-251

27. Gollust SE, Eisenberg D \& Golberstein E: Prevalence and correlates of self-injury among university students. Journal of American College Health 2008; 5:491-498

28. Gratz KL: Targeting emotion dysregulation in the treatment of self-injury. Journal of Clinical Psychology 2007; 63:11,1091-1103

29. Gratz KL \& Chapman AL: The role of emotional responding and childhood maltreatment in the development and maintenance of deliberate self-harm among male undergraduates. Psychology of Men \& Masculinity 2007; 8:1,1-14

30. Haas B \& Popp F: Why do people injure themselves? Psychopathology 2006; 39:10-18

31. Hardt $J$ \& Rutter M: Validity of adult retrospective reports of adverse childhood experiences: Review of the evidence. Journal of Child Psychology and Psychiatry 2004; 45:260-273

32. Hasking P, Momeni R, Swannell $S \&$ Chia $S$. The Nature and extent of non-suicidal self-injury in a non-clinical sample of young adults. Archives of Suicide Research 2008; $12: 208-218$

33. Hawton K, Fagg J, Simkin S, Bale E \& Bond A: Trends in deliberate self-harm in Oxford, 1985-1995: Implications for clinical services and the prevention of suicide. British Journal of Psychiatry 1997; 171:556-560

34. Hawton K, Bergen H, Casey D, Simkin S, Palmer B, Cooper $J$, et al.: Self-harm in England: A Tale of three cities. Social Psychiatry and Psychiatric Epidemiology 2007; 42:513-521

35. Hawton $K$, Rodham $K$, Evans $E \&$ Weatherall $R$ : Deliberate self-harm in adolescents: Self- report survey in schools in England. BMJ 2002; 325:1207-1211

36. Heat NL, Toste JR, Nedecheva $T$ \& Charlebois A: An examination of non-suicidal self- injury among college students. Journal of Mental Health Counseling 2008; 2:137-156

37. Herman J: Trauma and Recovery. 1992; New York: Basic Books.

38. Hovens JGFM, Wiersma JE, Giltay EJ, van Oppen P, Spinhoven P, Penninx, BWJH et al.: Childhood life events and childhood trauma in adult patients with depressive, anxiety and comorbid disorder vs. controls. Acta Psychiatrica Scandanavica, 2010; 122:66-74

39. Iffland B, Brahler E, Neuner F, Hauser $W$ \& Glaesmer $H$ : Frequency of child maltreatment in a representative sample of German population 2013; http://www.biomedcentral.com/1471-2458/13/980

40. Kaess, M, Parzer P, Mattern M, Plener PL, Bifulco A, Resch F, \& Brunner R: Adverse childhood experiences and their impact on frequency, severity, and the individual function of non-suicidal self-injury in youth. Psychiatry Research 2013; 206:265-272

41. Klonsky ED: Non-suicidal self-injury in United States adults: prevalence, socio-demographics, topography and functions. Psychological Medicine 2011; 41:1981-1986 
42. Klonsky ED: The functions of self-injury in young adults who cut themselves: Clarifying the evidence for affect regulation. Psychiatry Research 2009; 166:260-268

43. Klonsky ED: The functions of deliberate self-injury: $A$ review of the evidence. Clinical Psychology Review $2007 a ; 27: 226-239$

44. Klonsky ED: Non-suicidal self-injury: An introduction. Journal of Clinical Psychology 2007b; 63:1039-1043

45. Klonsky ED, \& Glenn CR: Assessing the functions of nonsuicidal self-injury: Psychometric properties of the Inventory of Statements about Self-injury (ISAS). Journal of Psychopathology and Behavioral Assessment 2009; 31:215-219

46. Klonsky ED, Oltmanns TF \& Turkheimer E: Deliberate self-harm in a non-clinical population: Prevalence and psychological correlates. American Journal of Psychiatry 2003; 160:1501-1508

47. Klonsky ED \& Moyer A: Child sexual abuse and nonsuicidal self-injury. The British Journal of Psychiatry 2008; 192:1-5

48. Laukkanen E, Rissanen ML, Honkalampi K, Kylma J, Tolmunen $T \&$ \& Hintikka J: The prevalence of self-cutting and other self-harm behaviors among 13 to 18year-old Finnish adolescents. Social Psychiatry and Psychiatric Epidemiology 2009; 44:23-28

49. Laye-Gindhu A \& Schonert-Reichl KA: Non-suicidal selfharm among community adolescents: Understanding the "whats" and "whys" of self-harm. Journal of Youth \& Adolescence 2005; 34:447-457

50. Matsumoto M, Azekawa T, Yamaguchi A, Asami T \& Iseki E: Habitual self-mutilation in Japan. Psychiatry and Clinical Neurosciences 2004; 58:191-198

51. Morey C, Corcoran P, Arensman E, Perry IJ: The prevalence of self-reported self-harming Irish adolescents. BMC Public Health 2008; doi: 101186/1471-2458-8-79

52. Motz A: The Psychology of Female Violence: Crimes against Body. 2008; Second edition, New York: Routledge

53. Muehlenkamp JJ \& Gutierrez PM: An investigation of differences between self-injurious behavior and suicide attempts in a sample of adolescents. Suicide and LifeThreatening Behavior 2004; 34:12-23

54. Nixon MK, Cloutier P \& Jansson SM: Non-suicidal selfharm in youth: a population-based survey. Journal of Canadian Medical Association 2008; 178:306-312

55. Nock MK: Why do people hurt themselves? New insights into the nature and functions of self-injury. Current Directions in Psychological Science 2009; 18:78-83

56. Nock MK, Prinstein MJ \& Sterba SK: Revealing the form and function of self-injurious thoughts and behaviors: A real time ecological assessment study among adolescents and young adults. Journal of Abnormal Psychology 2009; 118:816-827

57. Nock MK \& Mendes WB: Physiological arousal, distress tolerance, and social problem-solving deficits among adolescent self-injurers. Journal of Consulting and Clinical Psychology 2008; 76:28-38

58. Nock MK, \& Prinstein MJ: A functional approach to the assessment of self-mutilative behavior. Journal of Consulting and Clinical Psychology 2004; 72:885-890

59. Oktan V: A characterization of self-injurious behavior among Turkish adolescents. Psychological Reports 2014; 115: 645-654
60. Öksüz E \& Malhan S: Socioeconomic factors and health risk behaviors among university students in Turkey: Questionnaire study. Croatian Medical Journal 2005: 46:6673

61. Özgan S: Ergenlik döneminde dinlenilen müzik türü ile kendine zarar verme davranıșl arasındaki ilișki. Yayınlanmamış Yüksek Lisans Tezi, 2004; İstanbul

62. Polk E \& Liss M: Psychological characteristics of selfinjurious behavior. Personality and Individual Differences 2007; 43:567-577

63. Rallis, BA, Deming, CA, Glenn, JJ, \& Nock, MK: What is the role of dissociation and emptiness in the occurrence of non-suicidal self-injury? Journal of Cognitive Psychotherapy: An International Quarterly 2012; 26:287-298

64. Robertson CD, Miskey H, Mitchell $J$ \& Nelson-Gray R: Variety of self-injury: Number of different methods of nonsuicidal self-injury related to personality, psychopathology or functions of self-injury. Archives of Suicide Research 2013; 17:33-40

65. Ross $S \&$ \& Heath $N: A$ study of the frequency of selfmutilation in a community sample of adolescents. Journal of Youth \& Adolescence 2002; 3:67-77

66. Scher CD, Stein MB, Asmundson GJG, McCreary DR \& Forder DR: The Childhood Trauma Questionnaire in a community sample: Psychometric properties and normative data. Journal of Traumatic Stress: 2001; 14:843-857

67. Scoliers G, Portzky G, Madge N, Hewitt A, Hawton K, de Wilde EJ et al.: Reasons for adolescent deliberate selfharm: A cry of pain and/or a cry for help? Findings from the child and adolescent self-harm in Europe (CASE) study. Social Psychiatry and Psychiatric Epidemiology 2009; 44:601-607

68. Shi L: Childhood abuse and neglect in an outpatient clinical sample: Prevalence and impact. The American Journal of Family Therapy 2013; 41:198-211

69. Smith NB, Kouros CD \& Meuret AE: The Role of Trauma Symptoms in Non-Suicidal Self-Injury. Trauma Violence and Abuse 2014; 15:41-56

70. Somer O, Bildik T, Kabukcu-Basay B, Gungor D, Basay Ö \& Farmer RF: Prevalence of non-suicidal self-injury and distinct groups of self-injurers in a community sample of adolescents. Social Psychiatry and Psychiatric Epidemiology 2015; 50: 1163-1171

71. Suyemoto KL: The functions of self-mutilation. Clinical Psychology Review 1998; 18: 531-554

72. Taylor B: Exploring the perspectives of men who selfharm. Learning in Health and Social Care 2003; 2: 83-91

73. Toprak S, Çetin I, Güven T, Can $G$ \& Demircan Ç: Selfharm, suicidal ideation and suicide attempts among college students. Psychiatry Research 2011; 187: 140-144

74. Turner BJ, Chapman AL \& Layden BK: Intrapersonal and interpersonal functions of non-suicidal self-injury: Associations with emotional and social functioning. Suicide and Life-Threatening Behavior 2012; 42: 36-55

75. Uysal S: Kendine zarar verme davranışı olan genç erișkin hastalarda intihar girişimi olan ve intihar girişimi olmayanların klinik tanıları, borderline kişilik özellikleri, mizaç ve karakter özellikleri açısından karşılaștırılması. Psikiyatri Uzmanlık Tezi 2010; İstanbul.

76. van Camp I, Desmet M, \& Verhaeghe P:: Gender differences in non-suicidal self-injury: Are they on the verge of leveling off? 2011; 2nd International Conference on Behavioral, Cognitive and Psychological Sciences. 
77. van der Kolk BA: The compulsion to repeat the trauma. Psychiatric Clinics of North America 1989; 12: 389-411

78. van der Kolk BA, Roth S, Pelcovitz D, Sunday $S$ \& Spinazzola J: Disorders of extreme stress: The empirical foundation of complex trauma adaptation. Journal of Traumatic Stress 2005; 18: 389-399

79. van der Kolk BA, Perry JC \& Herman JL: Childhood origins of self-destructive behavior. American Journal of Psychiatry 1991; 148: 1665-1671

80. Walsh B: Treating self-injury: A practical guide. 2006; New York: Guilford Press

81. Walsh BW \& Rosen PM: Self-mutilation: Theory, research, and treatment. 1988; New York: The Guilford Press

82. White-Kress E, Gibson D \& Reynolds C: Adolescents who self-injure: Implications and strategies for school counselors. Professional School Counseling 2004; 7:195-201

83. Whitlock J, Eckenrode J \& Silverman D: Self-injurious behaviors in a college population. Pediatrics 2006; 117:1939-1948

84. Whitlock J, Muehlenkamp JJ, Purington A, Eckenrode J, Barreira, P, Abrams GB et al.: Non-suicidal self-injury in a college population: General trends and sex differences. Journal of American College Health 2011; 59:691-698

85. Yates TM: The developmental psychopathology of selfinjurious behavior: Compensatory regulation in posttraumatic regulation. Clinical Psychology Review, 2004; 24:35-74

86. Yates TM, Carlson EA \& Egeland B: A prospective study of child maltreatment and self-injurious behavior in a community sample. Developmental and Psychopathology 2008; 20: 651-671

87. Yates TM, Tracy AJ \& Luthar SS: Non-Suicidal selfinjury among "privileged youths": Longitudinal and cross-sectional approaches to developmental processes. Journal of Consulting and Clinical Psychology 2008b; 76: $52-62$

88. Zoroğlu SS, Tüzün Ü, Şar V, Tutkun H, Savaş HA, Öztürk $M$ et al.: Suicide attempt and self-mutilation among Turkish high school students in relation with abuse, neglect and dissociation. Psychiatry and Clinical Neurosciences 2003; 57: 119-126

Correspondence:

Meltem Idig-Camuroglu, $\mathrm{MD}, \mathrm{PhD}$

Bilted Psychotherapy Clinic

Cinnah Cad. 76/5, Ankara, Turkey

E-mail:meltemcamur@gmail.com 